\title{
Editorial
}

\section{Treatment of Cyclothymic Disorder: Commentary}

\author{
Ross J. Baldessarini ${ }^{a}$ b Gustavo Vázquez ${ }^{b, c}$ Leonardo Tondo ${ }^{b, d}$ \\ a Department of Psychiatry, Harvard Medical School and Psychopharmacology Program, McLean Division of

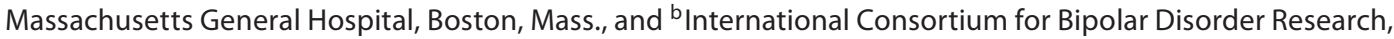 \\ McLean Division of Massachusetts General Hospital, Belmont, Mass., USA; ' Department of Neuroscience, \\ University of Palermo, Buenos Aires, Argentina; ${ }^{\mathrm{d}}$ Lucio Bino Mood Disorders Center, Cagliari, Italy
}

\section{Psychotherapy Trial by Fava and Colleagues}

This commentary was occasioned by the reporting of what appears to be the first randomized, controlled trial of psychotherapy in DSM-IV cyclothymic disorder [1]. It involved 62 untreated patients, randomized to psychiatrist-conducted psychotherapy versus usual (supportive, advisory) clinical care without antidepressant or moodstabilizing medication (benzodiazepines could continue at reduced doses). Importantly, the treatment conditions were closely matched for intensity at ten 45 -min sessions every 2 weeks for 5 months, with the exception of additional 'exposure homework' required for cognitive-behavioral therapy (CBT). The experimental intervention involved sequential use of CBT (first 6 sessions) aimed primarily at treating subsyndromal depression and anxiety symptoms $[1,2]$, followed by well-being therapy (final 4 sessions) originally designed to supplement moodstabilizing treatments in more severe bipolar disorder (BPD) and to reduce anxiety $[1,3]$. At baseline, participants were generally well-matched: average age 40 years, $50 \%$ were married, with an average of 5 years from estimated illness onset of DSM-IV cyclothymic disorder. By chance, initial ratings of depression severity were $15 \%$ higher among psychotherapy cases $(42.3 \pm 6.2$ vs.
$36.9 \pm 4.4 ; \mathrm{p}<0.001)$, but hypomania scores were only $0.76 \%$ greater $(9.26 \pm 3.10$ vs. $9.19 \pm 2.52)$ [1]. In addition, a small proportion (14.5\%) of subjects met DSM-IV criteria for type II BPD at some time, presumably after at least 2 years of cyclothymic disorder (table 1), indicating the presence of major depressive episodes and sustained hypomania [1]. Additional comorbidity involved anxiety disorders, but substance abuse and personality disorders were excluded.

Most participants (82.3\%) completed all 20 weeks of treatment $(83.5 \%$ given psychotherapy vs. $80.6 \%$ randomized to usual care). Depression ratings declined by $34.0 \%$ after 20 weeks of experimental treatment versus $15.2 \%$ among controls (a 2.2-fold difference). At the final assessment at 2 years of follow-up, these beneficial effects were sustained (37.1 vs. $18.7 \%$, respectively, a 2.0 -fold difference favoring psychotherapy). Hypomania ratings similarly improved by 36.3 versus $14.0 \%$, respectively, at 20 weeks ( 2.6 -fold), and by 48.1 versus $15.5 \%$ at 2 years (3.1fold difference). These differences between treatment arms were highly statistically significant [1]. The findings support the hypothesis that cyclothymic disorder is a treatable condition, and that the 5-month psychotherapy intervention offered showed substantial benefits that persisted for at least 2 years.

\section{KARGER}

Fax +41 613061234 E-Mail karger@karger.ch www.karger.com

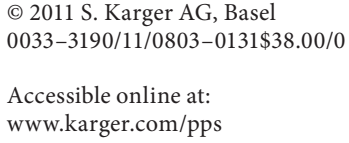

Dr. Ross Baldessarini

Mailman Research Center 312

McLean Hospital, 115 Mill Street

Belmont, MA 02467-9106 (USA)

Tel. +1 617855 3203, Fax +1 617855 3479, E-Mail rjb @ mclean.org 
Table 1. Current international diagnostic criteria for cyclothymic disorder

WHO International Classification of Diseases,

Tenth Revision (ICD-10, since 1990)

F34.0. Cyclothymia

Persistent instability of mood involving numerous periods of depression and mild elation, none of which is sufficiently severe or prolonged to justify a diagnosis of bipolar affective disorder (F31) or recurrent depressive disorder (F33). This disorder is frequently found in the relatives of patients with bipolar affective disorder. Some patients with cyclothymia eventually develop bipolar affective disorder. Can be diagnosed as a personality disorder in some cases.

APA Diagnostic and Statistical Manual, Fourth Edition

(DSM-IV, since 1994)

301.13. Cyclothymic disorder

1 A chronic mood disorder characterized by numerous depressive and hypomanic symptoms over at least 2 years (at least 1 year in children and adolescents), typically starting insidiously in adolescence or early adulthood.

2 No symptom-free period lasting 2 or more months.

3 At least 2 years without a major depressive, manic or mixed manic-depressive episode, although these sometimes emerge later.

4 Lack of explanation by another disorder or substance abuse.

5 Clinically significant distress from symptoms, or impairment in work, social or other important functions.

DSM-IV criteria allow for major depressive episodes (comorbid bipolar II disorder), typically after $\geq 2$ years of cyclothymic disorder.

\section{History of Cyclothymia}

The concept of cyclothymia dates at least to the mid or late 1800 s, although it had been largely ignored through most of the past century. It is one of several aspects of a current ferment in conceptualizations of mood disorders and in their nosological distinctions, including a widening range of BPD-like disorders and fragmentation of the broad 'major depression' concept into subtypes [4]. Usually, cyclothymia has been conceived as involving mild or moderate fluctuations of mood, thought, and behavior in what would now be considered 'subsyndromal' mild hypomanic or depressive-dysthymic directions, without meeting formal diagnostic criteria for either major depressive disorder (MDD) or hypomania. However, the sharp differentiation of cyclothymia as a discrete psychopathological syndrome (cyclothymic disorder) rather than a temperament or personality type, or mild phases of BPD, has been a challenge [5]. DSM-IV criteria require at least 2 years (1 year for juveniles) of mood shifts without major depression or mania, either as a distinct diagnosis, or as a precursor to major recurrences of depression or mania in BPD. From early reports, however, some patients with only cyclothymia and without major episodes of affective illness have been recognized.

Early, but relatively modern, descriptions of cyclothymia were provided by Karl Kahlbaum (1829-1899) as fluctuating conditions (cyclic partial insanity) including 'dysthymia' and 'hyperthymia' as milder forms of more typical cyclic insanity involving manic and melancholic phases; cyclothymia could either persist or evolve into more severe cyclic insanity [6]. Further descriptions were provided by Kahlbaum's associate Ewalt Hecker (1843-1909), who ascribed the concept to Kahlbaum from as early as 1877 [7]. This condition was also included among milder forms of illness or personality types within a broad range of manicdepressive disorders by Emil Kraepelin (1856-1926) by the end of the 19th century [8]. More recently, cyclothymia was considered a personality disorder in DSM-III (1980), and as a distinct disorder in both ICD-10 (since 1990) [9] and DSM-IV (since 1994) [10], provided that clinically significant distress and disability were present so as to support the designation of 'disorder'. ICD-10 considers the possibility of cyclothymia as either a disorder or a personality type [9]. DSM-IV criteria allow for the possibility of evolution of cyclothymic disorder into (or comorbidity with) $\mathrm{BPD}$, perhaps most often as bipolar II disorder (with major depression and hypomania) at later times [10] (table 1).

\section{Current Status of Cyclothymia}

There is considerable remaining ambiguity regarding cyclothymia as a distinct disorder, a temperamental or personality type, a precursor state to $\mathrm{BPD}$, or as lying within a 'bipolar spectrum' of related disorders $[5,10,11]$. Even the diagnosis can be clinically difficult since many cyclothymic patients do not recognize mild hypomania as psychopathological, and the distinctions between subsyndromal and syndromal hypomania and depression can be unclear. Cyclothymic disorder can be difficult to distinguish from type II BPD, and can resemble personality disorders including 'borderline' states $[5,10,11]$. Many basic epidemiological, clinical, and therapeutic characteristics of cyclothymia remain remarkably underdeveloped for a condition that has been widely recognized for more than a century. Estimates of the lifetime prevalence of DSM-IV cyclothymic disorder or temperament have been reported at $0.4-1.0 \%$ of nonclinical pop- 
ulation samples [10-13]. Cyclothymia may represent a precursor state or a comorbid characteristic in an uncertain proportion (15-50\%) of cases of types I or II BPD [10, 14]. Risks for cyclothymic disorder and temperament appear to be similar in men and women, to have a minor female preponderance and a greater chance of women to present for treatment $[10,13]$. First-degree relatives of $\mathrm{cy}$ clothymic disorder probands have an excess of BPD or MDD and, conversely, there is an excess of cyclothymia among relatives of identified BPD patients $[10,15]$. However, there is a lack of clarity about: (1) the stability of the disorder over time, (2) the proportion of early subsyndromal and later major hypomanic, depressive, or mixed states in the course of disorders considered primarily cyclothymic, (3) typical cycling rates as well as the frequency and duration of intervening periods of stability, and (4) risks of suicidal behavior. Typically, mood shifts appear to be more or less continuous in cyclothymia $[5,10$, 11] with parallels to rapid-cycling forms of BPD [16-18], and a close association with type II BPD $[19,20]$. Early cyclothymia in childhood may have predictive utility in anticipating later development of BPD [21,22].

In an effort to clarify the distribution of cyclothymic temperament with major mood disorders, we recently characterized temperament types among 1,870 mood disorder patients [type I BPD, $\mathrm{n}=419$; type II $\mathrm{BPD}, \mathrm{n}=308$; unipolar MDD (UP-MDD), $\mathrm{n}=1,143$ ] both clinically and by application of the TEMPS-A auto-questionnaire [23] to 174 of these (type I BPD, $\mathrm{n}=54$; type II BPD, $\mathrm{n}=41$; UPMDD, $n=79)$, all evaluated, treated, and followed at a Sardinian mood disorder center [Tondo et al., unpubl. data]. The prevalence of patients considered to be cyclothymic averaged $12.6 \%$ overall, and was only slightly higher among women (13.7\%) than men (10.8\%). However, the distribution of cyclothymic temperament differed highly by DSM-IV diagnosis, ranking: type II BPD (25.6\%), type I BPD (17.7\%), UP-MDD $(7.3 \%) ; \chi^{2}($ d.f. $=2)$ $=86.8, \mathrm{p}<0.0001$. Moreover, DSM-IV lifetime rapid cycling ( $\geq 4$ recurrences/year) was strongly associated with type II BPD, ranking: type II BPD $(31.4 \%) \geq$ type I BPD (7.31\%) > > UP-MDD (0.00\%), and the estimated cycling rate (episode recurrences/year $\pm \mathrm{SD}$ ) ranked: type II BPD $(3.26 \pm 8.11 \%) \geq$ type I BPD $(2.32 \pm 3.65 \%)>>$ UP$\operatorname{MDD}(0.98 \pm 1.55 \%)$. We also found a marked (4.5-fold) difference in rates of lifetime rapid cycling between patients diagnosed with $(16.8 \%)$ or without $\left(3.70 \% ; \chi^{2}=35.6\right.$, $\mathrm{p}<0.0001)$ TEMPS-A cyclothymic temperament [Tondo et al., unpubl. data]. These observations support the hypotheses that cyclothymia is strongly associated with $\mathrm{BPD}$, especially type II, and with relatively rapid cycling.

\section{Treatment of Cyclothymic Disorder}

There is broad agreement that treatment of cyclothymic disorder is appropriate when there is substantial clinical distress or dysfunction associated with depressive or hypomanic phases of the illness, or with severe emotional instability itself. Many such patients are far more distressed by the depressive or dysthymic component of the disorder, and are likely to present clinically demanding antidepressant treatment. However, the value of antidepressants is not sufficiently well studied to provide firm conclusions about either benefit or risks of additional affective destabilization, especially with continued, longterm, exposure to antidepressants or other mood-elevating drugs. Moreover, mixed states involving simultaneous or rapidly fluctuating combinations of dysphoric and hyperactive states are particularly poorly characterized in cyclothymic disorder. Both the risks of inducing or worsening of subsyndromal (or syndromal) hypomanic or mixed states with antidepressants in cyclothymic disorder patients, and their treatment or prevention by mood-stabilizing drugs are very little studied. In our recent review of BPD patients in the Sardinian mood disorder center, a cyclothymic temperament was, by far, the strongest predictor of the risk of switching into mania or hypomania [Tondo et al., unpubl. data; 24]. However, in cyclothymic disorder itself, as well as in type II BPD, there appears to be a limited risk of inducing hypomania or moderate mixed states during treatment with an antidepressant, even without a mood stabilizer [24, 25]. However, this impression is not adequately studied, and may in part reflect limited ability to become potentially dangerously manic in either cyclothymic disorder or in closely related type II BPD, with a risk of mood elevation being overlooked.

There is a growing clinical impression that mood-stabilizing agents, including lithium, several anticonvulsants, and some antipsychotic drugs, may offer particular value, at least for short-term treatment of type II BPD and perhaps also cyclothymic disorder [26-30]. Support for beneficial effects of quetiapine and lithium is particularly encouraging, but evidence pertaining to lamotrigine has been limited and inconsistent [26-30].

In addition, there is a small, but growing body of studies of psychosocial treatments in both type II BPD and cyclothymic disorder [3, 31-35]. Particularly promising results have been associated with applications of CBT and supportive groups in conjunction with mood-stabilizing medication [31, 32], although efforts to adjust the scheduling of circadian activities have had less benefit on mood 
stabilization [33]. Psychoeducational group treatments have demonstrated mood-stabilizing value in type II BPD [35], but require specific study in cyclothymic disorder.

\section{Conclusions}

The controlled trial of sequentially applied psychotherapies for cyclothymic disorder by Fava and his colleagues represents an important step forward in the evaluation of therapeutic implications of increasingly broad and numerous syndromes proposed to be related to BPD in both form and possibly also their therapeutics. As the complexity and subtyping of mood disorders continue to grow, there is increased challenge to support the concepts epidemiologically and clinically, with a particular need to improve matching of phenotypes with genetic and other biological assessments. Moreover, we propose that the potential clinical value of such complexity or broadening of diagnostic concepts calls for much more extensive and coherent evidence concerning the prognostic or predictive value of the concepts, as well as the efficacy, longterm effectiveness, specificity and safety of available means of treatment, with continued efforts to develop improved treatments.

\section{Acknowledgements}

This study was supported, in part, by a grant from the Bruce J. Anderson Foundation and by the McLean Private Donors Psychopharmacology and Bipolar Disorders Research Fund (to R.J.B.).

\section{Disclosure Statement}

None of the authors has any financial involvement with biomedical or pharmaceutical corporations that might appear to provide a potential conflict of interest in the reported material.

\section{References}

- 1 Fava GA, Rafanelli C, Tomba E, Guidi J, Grandi S: The sequential combination of cognitive behavioral treatment and well-being therapy in cyclothymic disorder. Psychother Psychosom 2011;80:136-143.

$\checkmark 2$ da Costa RT, Rangé BP, Malagris LE, Sardinha A, de Carvalho MR, Nardi AE: Cognitive-behavioral therapy for bipolar disorder. Expert Rev Neurother 2010;10: 1089-1099.

3 Fava GA, Tomba E: Increasing psychological well-being and resilience by psychotherapeutic methods. J Pers 2009;77:1903-1934.

$\checkmark 4$ Westermeyer J: Major depressive disorder with subthreshold bipolarity: exploring and managing new diagnoses. Am J Psychiatry 2010;167:1145-1147.

5 Howland RH, Thase ME: Comprehensive review of cyclothymic disorder. J Nerv Ment Dis 1993;181:485-493.

6 Baethge C, Salvatore P, Baldessarini RJ: On cyclic insanity (1882) by Karl Ludwig Kahlbaum, MD: translation and commentary. Harv Rev Psychiatry 2003;11:78-90.

7 Baethge C, Baldessarini RJ: Cyclothymia, a circular mood disorder (1893), classic text 55 by Ewald Hecker (translation). Hist Psychiatry 2003;14:391-399.

$>8$ Trede K, Salvatore P, Baethge C, Gerhard A, Maggini C, Baldessarini RJ: Manic-depressive illness: evolution in Kraepelin's textbook, 1883-1926. Harv Rev Psychiatry 2005; 13:155-178.
9 World Health Organization (WHO): International Classification of Diseases, Tenth Edition (ICD-10). Geneva, WHO, 1990.

10 American Psychiatric Association (APA): Diagnostic and Statistical Manual, Fourth revision (DSM-IV). Washington, American Psychiatric Press, 1994.

11 Goodwin FK, Jamison KR: Manic-Depressive Illness, ed 2. New York, Oxford University Press, 2007, pp 82-86.

12 Perugi G, Toni C, Maremmani I, Tusini G, Ramacciotti S, Madia A, Fornaro M, Akiskal HS: Influence of affective temperaments and psychopathological traits on the definition of bipolar disorder subtypes: study on bipolar I Italian national sample. J Affect Disord 2010, E-pub ahead of print.

13 Vázquez GH, Tondo L, Mazzarini L, Gonda $\mathrm{X}$ : Affective temperaments in general population: review and combined analysis from national studies. J Affect Disord, in press.

14 Mazzarini L, Pacchiarotti I, Colom F, Sani G, Kotzalidis GD, Rosa AR, Sanna L, De Rossi P, Girardi N, Bonnin CM, Sanchez-Moreno J, Vázquez GH, Gasto C, Tatarelli R, Vieta E: Predominant polarity and temperament in bipolar and unipolar affective disorders. J Affect Disord 2009;119:28-33.
$>15$ Vázquez GH, Kahn V, Schiavo CE, Goldchluk A, Herbst L, Piccione M, Saidman N, Ruggeri H, Silva A, Leal J, Bonetto GG, Zaratiegui R, Padilla E, Vilaprino JJ, Calvó M, Guerrero G, Strejilevich SA, Cetkovich-Bakmas MG, Akiskal KK, Akiskal HS: Bipolar disorders and affective temperaments: national family study testing the 'endophenotype' and 'subaffective' theses using the TEMPS-A Buenos Aires. J Affect Disord 2008;108:25-32.

16 Kilzieh N, Akiskal HS: Rapid-cycling bipolar disorder: overview of research and clinical experience. Psychiatr Clin North Am 1999; 22:585-607.

17 Hajek T, Hahn M, Slaney C, Garnham J, Green J, Růzicková M, Zvolský P, Alda M: Rapid cycling bipolar disorders in primary and tertiary care treated patients. Bipolar Disord 2008;10:495-502.

18 Lee S, Tsang A, Kessler RC, Jin R, Sampson N, Andrade L, Karam EG, Mora ME, Merikangas K, Nakane Y, Popovici DG, PosadaVilla J, Sagar R, Wells JE, Zarkov Z, Petukhova M: Rapid-cycling bipolar disorder: cross-national community study. Br J Psychiatry 2010;196:217-225.

19 Akiskal HS: Subaffective disorders: dysthymic, cyclothymic and bipolar II disorders in the 'borderline' realm. Psychiatr Clin North Am 1981;4:25-46. 
20 Hantouche EG, Akiskal HS: Toward a definition of a cyclothymic behavioral endophenotype: which traits tap the familiar diathesis for bipolar II disorder? J Affect Disord 2006; 96:223-237.

-21 Kochman FJ, Hantouche EG, Ferrari P, Lancrenon S, Bayert D, Akiskal HA: Cyclothymic temperament as a prospective predictor of bipolarity and suicidality in children and adolescents with major depressive disorder. J Affect Disord 2005;85:181-189.

22 Skjelstad DV, Malt UF, Holte A: Symptoms and signs of the initial prodrome of bipolar disorder: systematic review. J Affect Disord 2010;126:1-13.

-23 Akiskal HS, Akiskal KK, Haykal RF, Manning JS, Connor PD: TEMPS-A: progress towards validation of a self-rated clinical version of the Temperament Evaluation of the Memphis, Pisa, Paris, and San Diego Autoquestionnaire. J Affect Disord 2005;85:3-16.

24 Tondo L, Vázquez G, Baldessarini RJ: Mania associated with antidepressant-treatment: comprehensive meta-analytic review. Acta Psychiatr Scand 2010;121:404-414.
25 Amsterdam JD, Shults J: Efficacy and safety of long-term fluoxetine versus lithium monotherapy of bipolar II disorder: randomized, double-blind, placebo-substitution study. Am J Psychiatry 2010;167:792800.

26 Swartz HA, Thase ME: Pharmacotherapy for the treatment of acute bipolar II depression: current evidence. J Clin Psychiatry 2010, E-pub ahead of print.

27 Bisol LW, Lara DR: Low-dose quetiapine for patients with dysregulation of hyperthymic and cyclothymic temperaments. J Psycho pharmacol 2001;24:421-424.

28 Montes JM, Saiz-Ruiz J, Lahera G, Asiel A: Lamotrigine for the treatment of bipolar spectrum disorder: chart review. J Affect Disord 2005;86:69-73.

29 Vieta E: Defining the bipolar spectrum and treating bipolar II disorder. J Clin Psychiatry 2008;69:e12-e17.
30 Calabrese JR: Overview of patient care issues and treatment in bipolar spectrum and bipolar II disorder. J Clin Psychiatry 2008; 69:e18-e23.

31 Huxley NA, Parikh SV, Baldessarini RJ: Effectiveness of psychosocial treatments in bipolar disorder: state of the evidence. Harv Rev Psychiatry 2000;8:126-140.

32 Shen GH, Sylvia LG, Allloy LB, Barrett F, Kohner M, Iacoviello B, Mills A: Lifestyle regularity and cyclothymic symptomatology. J Clin Psychol 2008;64:482-500.

33 Totterdell P, Kellett S: Restructuring mood in cyclothymia using cognitive behavioral therapy: intensive time-sampling study. J Clin Psychol 2008;64:501-518.

34 Miklowitz DJ, Scott J: Psychosocial treatments for bipolar disorder: cost-effectiveness, mediating mechanisms, and future directions. Bipolar Disord 2009;11(suppl 2): $110-122$.

\$3 Colom F, Vieta E, Sánchez-Moreno J, Goikolea JM, Popova E, Bonnin CM, Scott J: Psychoeducation for bipolar II disorder: an exploratory, 5-year outcome subanalysis. J Affect Disord 2009;112:30-35. 